\title{
Cancer Therapy Using Antibiotics
}

\author{
Biplob Bhattacharya ${ }^{1 *}$, Sreya Mukherjee ${ }^{2}$ \\ ${ }^{1}$ TG United Inc., Brooksville, FL, USA \\ ${ }^{2}$ Department of Chemistry, University of South Florida, Tampa, FL, USA \\ Email: ${ }^{\text {bbhattac@mail.usf.edu }}$
}

Received 1 August 2015; accepted 1 September 2015; published 4 September 2015

Copyright (C) 2015 by authors and Scientific Research Publishing Inc.

This work is licensed under the Creative Commons Attribution International License (CC BY).

http://creativecommons.org/licenses/by/4.0/

(c) (i) Open Access

\begin{abstract}
Anticancer antibiotics have made a successful impact in the field of chemotherapeutics. For most of them, DNA is the molecular target. Some act as DNA intercalators or some prevent DNA repair among other mechanisms of actions, they are seen to have. The major disadvantages of these drugs though are the constant side effects and toxicities. With more focus on discovery of new drugs with newer scaffolds, the urge to discover and modify anticancer antibiotics is being lost. Modifications or even the wider research can yield newer better drugs for clinical use. The review here discusses the current antibiotic therapeutics, newer discoveries in the field as well ideas for future research.
\end{abstract}

\section{Keywords}

\section{Antibiotics, Lactams, Cancer, Mechanism of Action}

\section{Introduction}

Cancer therapy is as debilitating as the disease and though the global market for cancer drugs has hit billion dollars in annual sales the major limitation still remains with the toxicities that the drugs are associated with. Hence, new drug delivery techniques and drugs with diverse mechanisms of action are constantly sought after. For example, a new invention in the field of medical devices includes a method for treating cancerous tissue and nonmalignant tumors in combination with chemotherapy, for cell mass reduction and tissue dehydration using RF power via electrodes to heat the tumor tissue to around $45^{\circ} \mathrm{C}$ [1] or the discovery of novel small molecule derivatives of butyric acid with enhanced anticancer properties and solubility to function as prodrugs to release formaldehyde upon metabolic breakdown, showcase the immense effort put into both the arenas of research [2]. Chemotherapy, which is one of the predominant methods for treating cancer patients causes life-threatening side effects and development of drug resistance in cancer cells. This therapy (often abbreviated to chemo) falls under the category of cancer treatment that uses chemical substances, especially by use of one or more anti-cancer

\footnotetext{
${ }^{*}$ Corresponding author.
} 
drugs (chemotherapeutic agents) which stops or slows the growth of the cancer cells which have an alarming growth rate and in turn kills normal cells. This damage to the normal cells causes potential side effects [3]. The use of chemotherapy to treat cancer began at the start of the 20th century with attempts to screen chemicals using transplantable tumors in rodents. But the final impetus came from World War II-related programs, and the effects of drugs that were made during that time that Cancer Chemotherapy National Service Center came into being in 1955. There are currently different classes of compounds used in chemotherapy including alkylating agents, antimetabolities, anti-microtubule agents, topoisomerase inhibitors, mitotic inhibitors, cytotoxic antibiotics, and corticosteroids [4]. This review summarizes emerging efforts in combating cancer particularly with the help of antibiotics delivery systems.

\section{Principles of Cancer Development}

Normal cells can be differentiated from cancer cells with their ability of uncontrolled cell division mostly driven by interferences in form of mutations or others in the cell cycle. In cells, the cell cycle is divided into the following phases and is tightly controlled by different molecular switches as illustrated in Figure 1:

$\mathrm{G}_{0}$ - Also known as the resting phase where cells prepare themselves before division.

$\mathrm{G}_{1}$-Also known as the growth phase where the cell increases in size and prepares for the copy of DNA.

$S$ phase-The synthetic phase where cell chromatin material is doubled followed by the $G_{2}$ phase.

$\mathrm{G}_{2}$ phase-Where further growth occurs followed by mitosis.

Apart from cell growth another tightly regulated process in the cell, is cell death which occurs through apoptosis or necrosis mediated by a machinery of enzymes and proteins. The uncontrolled cell growth by the tumor cell is possible due to its control on these two important cellular processes. The kinetics of tumor growth is regulated by cell cycle time which varies in different tissues; growth fraction of cell achieved and cell death resulting from unsuccessful division, metastasis, and migration. Tumor cells are known to follow a sigmoidal growth curve depending on the tumor size. The tumor cell division is pronounced when the tumor size is small (almost double) and growth eventually normalizes and solely depends on blood supply availability and cell death control. Metastasis of a tumor is possible when it spreads beyond its original site and invades surrounding tissues. Some factors contributing to this are abnormalities in maintaining tissue integrity in the cells, excessive growth factor production and suppression of tumor suppressor genes [5].

\section{Antibiotic Chemotherapeutics in Cancer Therapy}

The purpose of cytotoxic chemotherapeutics is to successively reduce the gap between growth and death of cancer cells in each cycle of treatment [6]. It is known that different types of cancers behave differently, and are essentially caused by various factors including genetics, lifestyle, certain types of infections and environmental exposures to different types of chemicals such as tobacco, alcohol etc. and radiation [7]-[9]. Chemotherapy has come a long way in overcoming the pessimism about the ability of drugs to cure advanced cancers and also the use of screening molecules for potential new drugs and for targeted treatments. Although the biggest limitation for chemotherapy still stands at the dose at which it needs to be administered. Very low doses are seen to be ineffective against tumors, whereas excessive doses bring in immense toxicity to the patient [10].

Antibiotics which are used in chemotherapy have various modes of actions. Some are potent intercalating agents whereas some are DNA damagers. Study of different antibiotic cytotoxic agents including Actinomycin, Adriamycin/Doxorubicin and some other agents showed that stimulation and enhancement of existing host defense mechanisms is one of the additional ways that these chemotherapeutic agents exert their effects. DNA is one of the primary molecular targets for many of these chemotherapeutic drugs and is essentially viewed as a non-specific target of the cytotoxic agents. Discovery of new DNA specific drugs now have shown enhanced efficacy towards DNA itself and are hence anticipated to be far more specific and effective towards it. Nevertheless there are limitations of DNA targeted therapy as although they preferentially affect cancerous cells due to their high proliferation rate and genomic instability, but benign cells can also be affected in the process. Normal cells have the capacity to tolerate basal levels of DNA damage but the repair mechanisms are often too much for the cells to handle due DNA targeted therapeutics [11]. Anthracyclins, bleomycins, actinomycin D, mitomycins are a few anticancer antibiotics used in therapy. Figure 2 summarizes the mechanism of action of these antibiotics.

Anthracyclines are anticancer compounds that were originally derived from Streptomyces in the 1960s [12] 


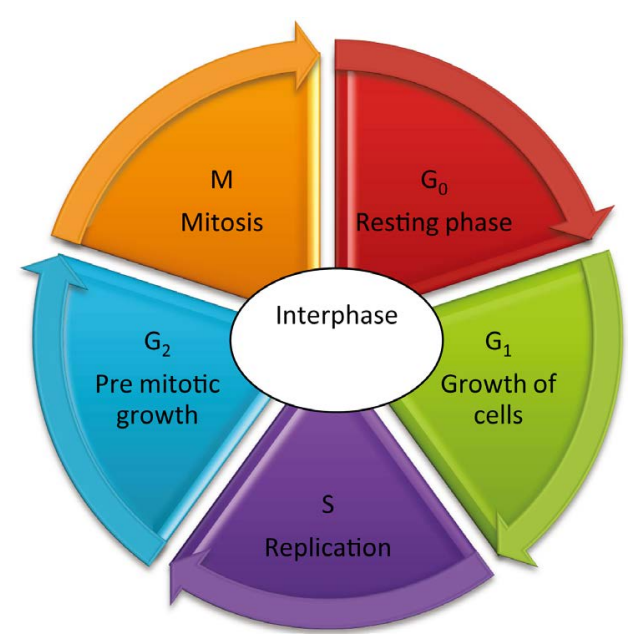

Figure 1. Cell cycle in a cell depicting the different stages it goes through.

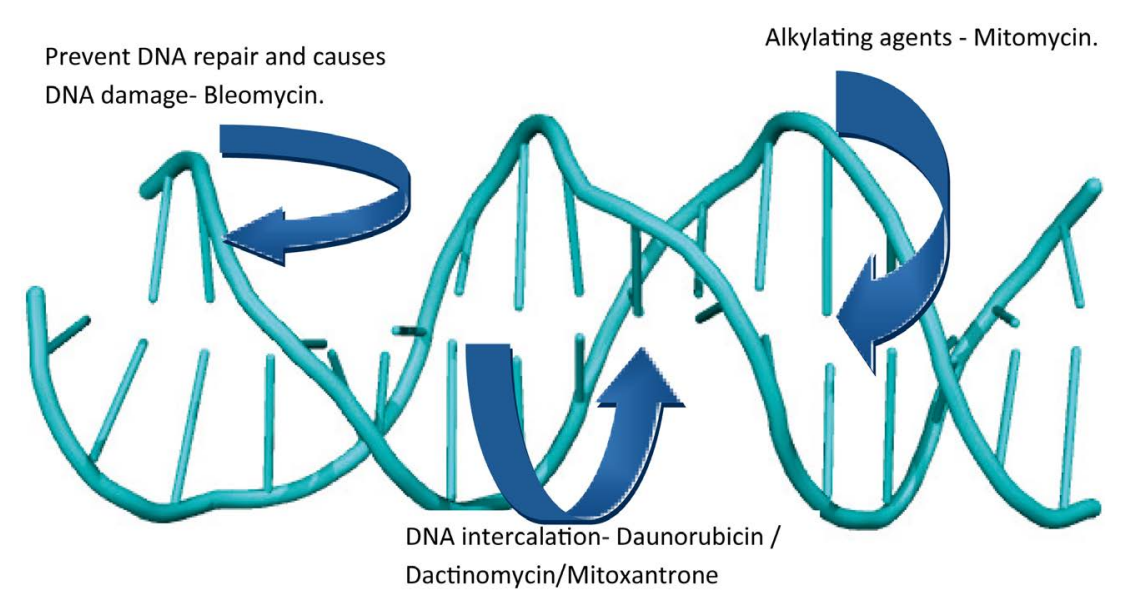

Figure 2. Mechanism of action of Anticancer Antibiotics.

and are aromatic polyketides. Doxorubicin and Daunorubicin were the first two anthracyclines discovered and were obtained from the bacterium Streptomyces peucetius. Daunorubicin, another anthracycline antibiotic structurally close to doxorubicin is used for treating leukemia. Doxorubicin which is a hydroxyl derivative of daunorubicin which is an anthracycline antibiotic works as an intercalating agent forms free radicals and alters membrane function [13]. It is one of the most effective drugs for solid tumor treatment, e.g., breast cancer, small cell lung cancer and ovarian carcinoma treatments. It also has activity against bladder, stomach, liver and thyroid tumors. But both these anthracyclines are known to produce resistance in the tumor cells, and also severe dose dependent cardiotoxicity, apart from other side-effects hence modification of these drugs structurally to produce analogs with wider activity and lower toxicity have thus been sought. The few clinically approved analogs include epirubicin and idarubicin [14] shown in Figure 3.

Epirubicin is an epimer of doxorubicin with the only difference being in the orientation of the C-4 hydroxyl group on the sugar and is used in the treatment of gastric lung, ovarian and breast cancer. This change decreases cardio toxicity of the drug as compared to others in the family. Idarubicin which is a structural analog of daunorubicin lacks the C-4 methoxy group thereby increasing its lipophilicity and is used for the treatment of acute myelogenous leukemia [15]. Another derivative of doxorubicin is Valrubicin which is used mainly in early bladder cancer, is a N-trifluoroacetyl, 1-4-valerate derivative of doxorubicin and enters cells more rapidly than doxorubicin [16]. Chemical structure of Valrubicin is shown in Figure 4.

The anthracycline antibiotics are known to produce DNA cleavable complexes and prevention of topoisomerase II activity aiding in prevention of DNA transcription and replication and also produce reactive oxidative species. One mechanism it works through for generation of reactive species is that upon electron addition to the 
<smiles>COc1cccc2c1C(=O)c1c(O)c3c(c(O)c1C2=O)C[C@@](O)(C(=O)CO)C[C@@H]3OC1C[C@H](N)[C@H](O)[C@H](C)O1</smiles><smiles>COc1cccc2c1C(=O)c1c(O)c3c(c(O)c1C2=O)C[C@@](O)(C(=O)CO)C[C@@H]3O[C@H]1C[C@H](N)[C@@H](O)[C@H](C)O1</smiles><smiles>COc1cccc2c1C(=O)c1c(O)c3c(c(O)c1C2=O)C[C@@](O)(C(C)=O)C[C@@H]3O[C@H]1C[C@H](N)[C@@H](O)[C@H](C)O1</smiles><smiles>CC(=O)C1(O)Cc2c(O)c3c(c(O)c2C(OC2C[C@H](N)[C@H](O)[C@H](C)O2)C1)C(=O)c1ccccc1C3=O</smiles>

Figure 3. Chemical structures of commonly used Anthracycline Antibiotics.<smiles>CCCCC(=O)OCC(=O)[C@]1(O)Cc2c(O)c3c(c(O)c2[C@@H](OC2CC(NC(=O)C(F)(F)F)C(O)C(C)O2)C1)C(=O)c1c(OC)cccc1C3=O</smiles>

Figure 4. Chemical structure of Valrubicin.

quinone moiety in the $\mathrm{C}$ ring leads to formation of a semiquinone that releases reactive oxygen species to go back to the quinone form. Again, oxidation of the semiquinone would produce a aglycone that has higher solubility in lipids and can hence intercalate into biological membranes and form reactive oxygen species They are also postulated to bind to the proteasome thereby showing that anthracyclines can also inhibit cell growth through antiangiogenic pathways. Figure 5 depicts binding of an anthracycline antibiotic to DNA [13] [17].

The side effects of anthracyclines, like any other chemotherapeutic agent, are linked to their cytotoxicity to non-differentiated, proliferating normal cells. These side effects include nausea, vomiting, and alopecia. The major toxicities of anthracyclines however include cardiotoxicity which is irreversible and myelosuppression. Doxorubicin can also cause severe tissue necrosis. Use of anthracycline for pediatrics is a careful consideration due to its irreversible cardio toxicity effects [18].

Actinomycin is a complex molecule that intercalates DNA and prevents RNA synthesis [19]. Mitoxanthrone, a quinone antibiotic has lower toxicities as compared to anthracycline antibiotic drugs [20]. Bleomycin, another class of antibiotics which include bleomycinic acid, BLMA2, and B2 are also structurally related phleomycinins and tallysomycins, are a family of glycopeptide derived antibiotics isolated from the Streptococcus verticullis species and are essentially used with other agents for treating tumors like squamous cell carcinomas and malignant lymphomas [21] [22]. The basic core structure consists of the basic glycopeptide with a pyrimidine chromophore linked to a propanamide, a $\beta$ aminoalanine amide and L-glucose and 3-O carbmoyl-d-mannose. A tripeptide chain and a bithiazole moiety are attached to this core. The major issue of this drug is early drug resistance and pulmonary toxicity. Their mode of action is exerted using sequence selective metal dependent oxidative cleavage of DNA and RNA in the presence of oxygen, mitochondrial damage and also DNA fragmentation. They have been seen to produce abnormal $G_{2}$ phase cells during cell cycle. Other adverse effects include significant skin reactions, erythema and gastric ulcers [23]. 


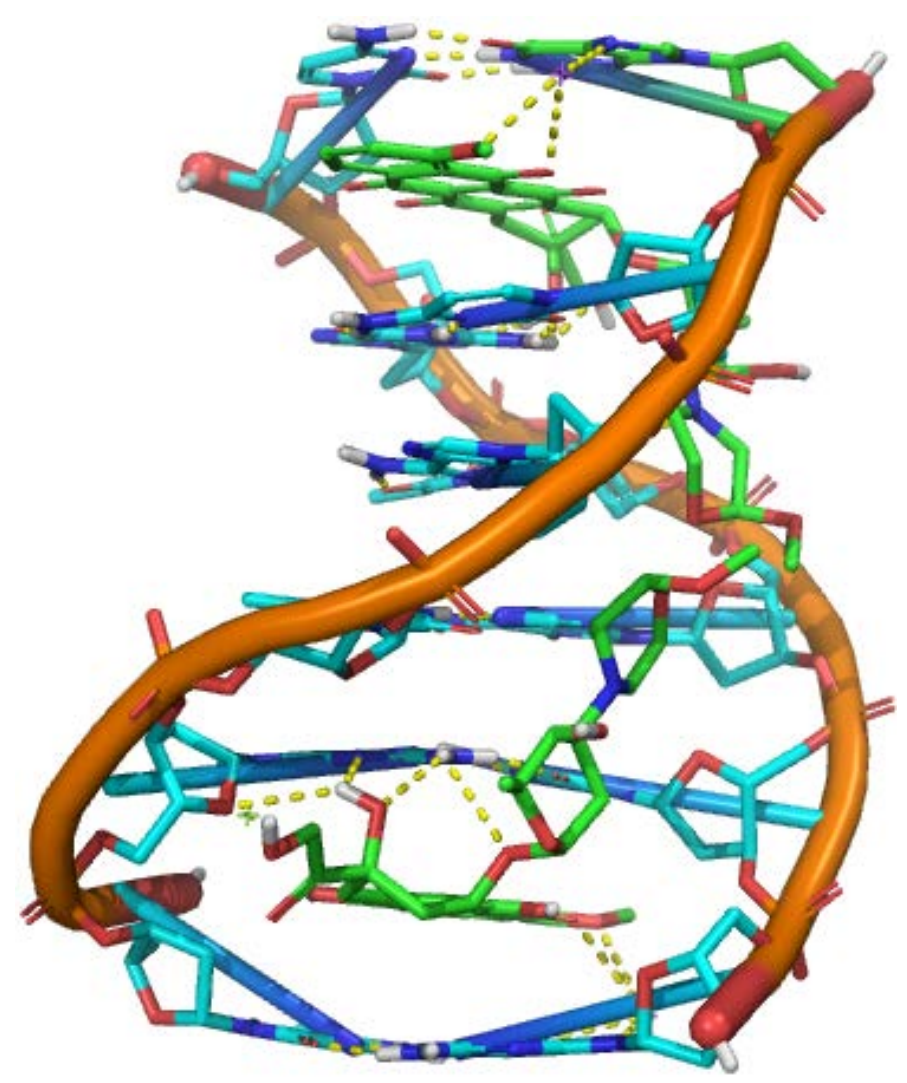

Figure 5. DNA binding of anthracycline antibiotic doxorubicin. Antibiotic is depicted in green with its interactions with neighboring residues. Crystal structure retrieved from PDB ID: 2DES (1.5 $\AA)$.

Mitomycin, class of antibiotics is a broad spectrum antibiotic and in contrast to others form covalent linkages to DNA and function as bioreductive alkylating agents in the absence of oxygen [24]. They were isolated from the broth culture of Streptomyces caespitosus. The core structure is a configuration of a quinone, an aziridine and a carbamate moiety around a pyrrole 1,2-indole nucleus. The mechanism of action involves crosslinking of two complementary strands of DNA and attachment of the drug to a single strand for alkylation. Reduction of the quinone moiety makes the drug a potent alkylator and the acid activation considering the acidic environment around tumor cells, of mitomycin is a second mechanism that activates it as an alkylater. It is also postulated to form reactive oxidative species apart from alkylation. The side effects are often unpredictable and dose dependent. Anorexia, necrosis, and ulcers have been reported for most patients. Pulmonary reactions anemia, renal failure have also been indicated with this treatment.

Another class of antibiotics is the enediyne antibiotics that are very amenable for design and have remarkable biological activity. Their anticancer activity is apparently due to their ability to damage DNA through radical-mediated hydrogen abstraction. The enediyne antibiotics show markedly cytotoxicity's against cancers in vitro and in vivo [25]. One example of this class is Lidamycin.

\section{Antibiotic Research Advantages and Disadvantages}

The antibiotics used in cancer are named so as they are extracted from active microbes and were also the first agents used as anticancer drugs. In general, antibiotics have been used in the treatment of bacterial, fungal and protozoal infections and some physiological diseases. Microbes in their constant fight for survival produce new metabolites and products due to their flexible metabolic strength. Microorganisms continue to interact with the physical, chemical, biological and social environment to bring about changes in them which is probably a major reason for resistance development. Resistance development and toxicities associated with these drugs, discovery of new drug scaffolds with the help by HTS (high throughput screening) and them being pursued have given rise 
to other cytotoxic agents with different modes of actions. Economic reasons have also added to the somewhat diminishing area of antibiotic search. The major concern for these drugs lies in the fact that they affect rapidly dividing cells and do not target cells at the resting phase. Hence control of metastasis and differentiation cannot be achieved effectively by these drugs. And as discussed earlier the side-effects ranging from vomiting, nausea, mucotisis, bone marrow suppression to cardio toxicity and many more cannot be ignored. Nevertheless, this arena still has the possibility of success if pursued considering the plethora of microbes that are out there. There is some if not none interest in finding newer anticancer antibiotics, some as derivatives of the known clinically approved drugs and some newer ones. But tapping into nature and finding newer moieties needs to be done not only to develop newer drugs but also to understand how these new metabolites are being formed by different microbes. A few approaches that can be taken to initiate this include the classical fermentation approach, rational drug design followed by total synthesis of these compounds and also combination approaches to design compounds from known drugs [26]. Currently approved antibiotics used clinically are shown in Table 1 [27].

\section{New Research in the Field}

New research in the field of enediyne antibiotics include the discovery of Lactoquinomycin, which is similar to medermycin but can be differentiated from medermycin by the physico-chemical properties and anticancer activity. Lactoquinomycin is seen to be more stable with significant antitumor activity [28]. N1999A2 another newly discovered 9-membered enediyne, based natural product has anticancer effects in human cancer cells. It has a chromophore similar to a neocarzinostatin and is found to be considerably stable in nature, with DNA intercalation into the minor groove. The difference in mode of action between the two is solely based on the presence or absence of an aminoglycoside residue [24]. Improvement of drug delivery techniques for some of these antibiotics have also resulted in accelerated release of the drug for e.g. doxorubicin. $\mathrm{pH}$-responsive flower-like micelles consisting of two hydrophobic blocks and one hydrophilic block at physiological $\mathrm{pH}$ when made. As the $\mathrm{pH}$ changed to slightly acidic as in tumor extracellular $\mathrm{pH}$, the flower-like micelles underwent a change in the hydrophobicity of the micellar core resulting in disintegration of the micellar core thereby allowing accelerated drug release [29]. Reduction-sensitive polymeric nanocarriers with near-infrared fluorescence probes were also prepared for doxorubicin. These revealed to have an accelerated release behavior in the presence of glutathione. Cellular uptake studies showed that they could enter cell via endocytosis and had enhanced permeability and retention effects [30]. Nanoparticles of Doxorubicin have been found to have sustained dosage and show increase in their therapeutic effect [31] [32]. In the recent years, there has been considerable research in re-understanding the older antibiotics and also finding new ones. Distamycin, an antibiotic is known to specifically target the minor groove of DNA. Another class of compounds, the lexitropins which contain a thiazole moiety and very related to Distamycin have also showed similar modes of action [33]. Chromomycin A3 which is an anthraquinone antibiotic is produced at the fermentation of Streptomyces griseus is known to block macromolecule synthesis via reversible interaction with DNA template only in the presence of divalent metal ions such as $\mathrm{Mg}^{2+}$. New studies unearthed that the formation of two types of complexes occurs with different stoichiometry's and formation constants, a 1:1 and a 2:1 stoichiometry in terms of chromomycin $\mathrm{A} 3$ and $\mathrm{Mg}^{2+}$ with different binding affinity to DNA [34] [35]. Mithramycin, which is now a discontinued drug and is also called plicamycin, was a DNA-binding, anti-tumor antibiotic which too was originally isolated from Streptomyces griseus, had been used as a chemotherapeutic agent, acts via the inhibition of replication, and transcription. It too blocked macromolecular biosynthesis via reversible interaction with DNA in the presence of bivalent cation such as $\mathrm{Mg}^{2+}$. This antibiotic is also known to form two types of complexes with $\mathrm{Mg}^{2+} 1: 1$ and 2:1 in terms of the $\mathrm{Mg}^{2+}$ complex [36].

Table 1. Clinically approved antibiotics with their brand names.

\begin{tabular}{cc}
\hline Brand Name & API \\
\hline Adriamycin & Doxorubicin hydrochloride \\
Cerubidine/Doxil & Daunorubicin hydrochloride \\
Cosmegen & Dactinomycin \\
Idamycin/Zavedos & Idarubicin hydrochloride \\
Novantrone & Mitoxantrone hydrochloride \\
Mitozytrex/Mutamycin & Mitomycin C \\
\hline
\end{tabular}


It's interactions with $\mathrm{Zn}^{2+}$ was studied and it was seen that it too is another physiologically important bivalent cation as it acts as a cofactor. Nevertheless, it is been seen that it forms only one kind complex with $\mathrm{Zn}^{2+}$ in the mole ratio of 2:1 in terms of antibiotic with affinity higher than the corresponding dimer complex with $\mathrm{Mg}^{2+}$ ion [37]. Leinamycin, has been discovered as a new class of antibiotic which contains an 18-membered macrolactam that works as a DNA-damaging agent by causing oxidative DNA damage and DNA alkylation mediated by a episulfonium ion and has been found to be highly toxic and potent against all the cell cycle stages [38]. Another antibiotic, Dynemicin, a natural product derived out of microbial fermentation of the indigenous bacteria $\mathrm{Mi}$ cromonospora chersina is found to be an exceedingly potent antitumor antibiotic that cleaves double-stranded DNA in vitro in the presence of activating factors such as NADPH or glutathione. It is a striking hybrid structure of both anthraquinone as a DNA intercalator and diynene as a DNA strand breaker. Various new forms of this class have been tested successfully [39]. Several classes of FDA-approved antibiotics that inhibit mitochondrial biogenesis as a known "side-effect" have been harnessed instead as a "therapeutic effect". Mitochondria acts as the source of energy and very importantly for division for the stem cells a crucial process which if goes wrong leads to cancer. These stem cells are strongly associated with the growth and recurrence of all cancers and are especially difficult to eradicate with normal treatment, which also leads to tumors developing resistance to other types of therapy. Mitochondria and bacteria have evolutionary connections and thus some of the antibiotics also affect mitochondria. A few different classes of FDA-approved drugs doxycycline and azithromycin, both have been tested and have already shown positive therapeutic effects in cancer patients which opens up another venue for drug discovery [40]. Quinolone antibiotics play a role as an adjunct to intravesical chemotherapy for bladder cancer. Ciprofloxacin and ofloxacin are seen to exhibit significant time- and dose-dependent cytotoxicity against transitional carcinoma cells and enhance the effect of doxorubicin within tolerable toxicities in patients [41]. A new actinomycete strain L033 discovered from Streptomyces avermitilis, strongly inhibited in vitro proliferation of human hepatoma, chronic myelogenous leukemia, and colonic carcinoma cell lines and was seen to be able to produce a high quantity of oligomycin-A. Hence, the potential use of this strain for scale up of oligomycin is immense [42]. Dexrazoxane, which is a cardioprotective agent for use in conjunction with doxorubicin has shown the ability to prevent the devastating tissue necrosis after anthracyclines use and hence is the first and only proven antidote in anthracycline extravasation [43]. A lactam analog of Actinomycin D was newly synthesized as a potential antitumor chemotherapeutic agent. It was deduced that the lactone and lactam actinomycins acquired a similar environment when bound to DNA and hence the desired effect [12] [44]. Ascofuranone, an antibiotic produced by the fungus Ascochyta viciae has also been reported to have anti-tumor activity [45]. The compound exhibited general inhibitory effects on the macromolecular syntheses and inhibited hypotonic hemolysis [46].

Moving to finally where it all started from. Penicillin, the first antibiotic developed for the therapy of bacterial infectious diseases have also found new applications as anti-cancer prodrugs and enzyme inhibitors [47]. Several studies have reported on the anticancer properties of the $\beta$-lactams. N-methylthio $\beta$-lactams, a new class of drugs was found to induce apoptotic behavior in a number of cancer cell lines, including human breast, prostate, leukemia, and head-and-neck. The chemical structure has been shown in Figure 6 .

The $\beta$-lactams caused DNA damage and the inhibition of DNA replication in Jurkat T cells. The result of this was activation of p38 mitogen-activated protein kinase, as well as S-phase arrest and cellular apoptosis leading to caspase activation. It was seen that DNA cleavage occurred in a time-dependent and concentration-dependent manner, before stagnation occurred in the S-phase cell cycle, and in a manner inversely proportional to the size of the organothio side chain of the $\beta$-lactam used. $\beta$-lactam antibiotics playing a primary role in cancer chemotherapy as no deleterious effects in the mice, or any cellular toxicity to normal cells in vitro was observed for the first time [48]. Nanoantibiotics, in principle provide for a new paradigm for treating infectious diseases using nanomaterials. Antimicrobial nanoparticles (NPs) and nanosized carriers use for antibiotics delivery can be envisaged for the future. They have proven their effectiveness for treating infectious diseases, including antibiotics resistant ones, in vitro as well as in animal models hence [49] their use in anticancer antibiotic delivery is something that can be foreseen in the future.

\section{Future Directions and Conclusion}

As discussed earlier, antibiotics as anticancer drugs clearly form an important part of chemotherapeutics with curative properties. With its use as antibacterials and also anticancer drugs, they have come a long way in proving their worth. But even decades of research has not addressed the overall toxicities involved with them which 

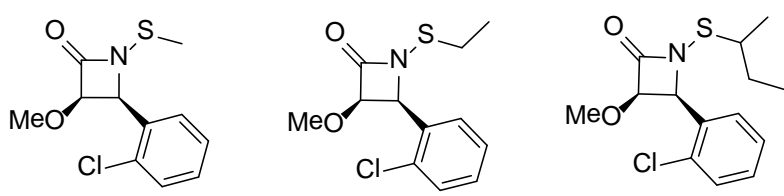

Figure 6. N-methylthio $\beta$-lactam, N-ethylthio $\beta$-lactam, and N-sec-butylthio $\beta$-lactam.

is a point of genuine concern although follow up medications are provided to ease patients in those respects. The research in this area needs to take back up to not only make newer safer derivatives of known drugs but also look into finding newer drug scaffolds. Significant changes in parent chemical structures and newer classes of antibiotics can provide a chance for this field to boom again. Although chemotherapeutics has seen newer mechanistic drugs; antibiotics still continue to show their remarkable properties as important drugs for the masses. The newer discovered drugs have hope for more effective drugs in the future and with the growth of drug delivery techniques and newer moieties, control of toxicity will be an achievable task in the near future with these chemotherapeutics [50].

\section{References}

[1] Curley, S.A., Izzo, F., Delrio, P., Ellis, L.M., Granchi, J., Vallone, P., Fiore, F., Pignata, S., Daniele, B. and Cremona, F. (1999) Radiofrequency Ablation of Unresectable Primary and Metastatic Hepatic Malignancies: Results in $123 \mathrm{~Pa}$ tients. Annals of Surgery, 230, 1-8. http://dx.doi.org/10.1097/00000658-199907000-00001

[2] Nudelman, A., Gnizi, E., Katz, Y., Azulai, R., Cohen-Ohana, M., Zhuk, R., Sampson, S.R., Langzam, L., Fibach, E., Prus, E., Pugach, V. and Rephaeli, A. (2001) Prodrugs of Butyric Acid. Novel Derivatives Possessing Increased Aqueous Solubility and Potential for Treating Cancer and Blood Diseases. European Journal of Medicinal Chemistry, 36, 63-74. http://dx.doi.org/10.1016/S0223-5234(00)01199-5

[3] Corrie, G.P. (2008) Cytotoxic Chemotherapy: Clinical Aspects. Medicine, 36, 24-28. http://dx.doi.org/10.1016/j.mpmed.2007.10.012

[4] De Vita Jr., V.T. and Chu, E. (2008) A History of Cancer Chemotherapy. Cancer Research, 68, 8643-8653. http://dx.doi.org/10.1158/0008-5472.CAN-07-6611

[5] Payne, S. and Miles, D. (2008) Mechanisms of Anticancer Drugs. CRC Press, 34-46. http://cw.tandf.co.uk/scottbrownent/sample-material/Chapter-4-Mechanisms-of-anticancer-drugs.pdf http://dx.doi.org/10.1201/b15118-6

[6] Skipper, H.E., Schabel, F.M. and Wilcox, W.S. (1964) Experimental Evaluation of Potential Anticancer Agents. XIII. On the Criteria and Kinetics Associated with "Curability" of Experimental Leukemia. Cancer Chemotherapy Reports, 35, 1-111.

[7] Schütze, M., Boeing, H., Pischon, T., Rehm, J., Kehoe, T., Gmel, G., Olsen, A., Tjønneland, A.M., Dahm, C.C., Overvad, K., Clavel-Chapelon, F., Boutron-Ruault, M.C., Trichopoulou, A., Benetou, V., Zylis, D., Kaaks, R., Rohrmann, S., Palli, D., Berrino, F., Tumino, R., Vineis, P., Rodríguez, L., Agudo, A., Sánchez, M.J., Dorronsoro, M., Chirlaque, M.D., Barricarte, A., Peeters, P.H., van Gils, C.H., Khaw, K.T., Wareham, N., Allen, N.E., Key, T.J., Boffetta, P., Slimani, N., Jenab, M., Romaguera, D., Wark, P.A., Riboli, E. and Bergmann, M.M. (2011) Alcohol Attributable Burden of Incidence of Cancer in Eight European Countries Based on Results from Prospective Cohort Study. BMJ, 342, d1584. http://dx.doi.org/10.1136/bmj.d1584

[8] Sasco, A.J., Secretan, M.B. and Straif, K. (2004) Tobacco Smoking and Cancer: A Brief Review of Recent Epidemiological Evidence. Lung Cancer, 45, S3-S9. http://dx.doi.org/10.1016/j.lungcan.2004.07.998

[9] Anand, P., Kunnumakkara, A.B., Sundaram, C., Harikumar, K.B., Tharakan, S.T., Lai, O.S., Sung, B. and Aggarwal, B.B. (2008) Cancer Is a Preventable Disease That Requires Major Lifestyle Changes. Pharmaceutical Research, 25, 2097-2116. http://dx.doi.org/10.1007/s11095-008-9661-9

[10] Foote, M.A. (1998) The Importance of Planned Dose of Chemotherapy on Time: Do We Need to Change Our Clinical Practice? The Oncologist, 3, 365-368.

[11] Tacar, O., Sriamornsak, P. and Dass, C.R. (2013) Doxorubicin: An Update on Anticancer Molecular Action, Toxicity and Novel Drug Delivery Systems. Journal of Pharmacy and Pharmacology, 65, 157-170. http://dx.doi.org/10.1111/j.2042-7158.2012.01567.x

[12] Brockmann, H. (1963) Anthracyclinones and Anthracyclines. (Rhodomycinone, Pyrromycinone and Their Glycosides). Fortschritte der Chemie organischer Naturstoffe, 21, 121-182. 
[13] Zunino, F. and Capranico, G. (1990) DNA Topoisomerase II as the Primary Target of Anti-Tumor Anthracyclines. Anti-Cancer Drug Design, 5, 307-317.

[14] Arcamone, F. (1985) Properties of Antitumor Anthracyclines and New Developments in Their Application: Cain Memorial Award Lecture. Cancer Research, 45, 5995-5999.

[15] Cortes-Funes, H. and Coronado, C. (2007) Role of Anthracyclines in the Era of Targeted Therapy. Cardiovascular Toxicology, 7, 56-60. http://dx.doi.org/10.1007/s12012-007-0015-3

[16] Kuznetsov, D.D., Alsikafi, N.F., O’Connor, R.C. and Steinberg, G.D. (2001) Intravesical Valrubicin in the Treatment of Carcinoma in Situ of the Bladder. Expert Opinion on Pharmacotherapy, 2, 1009-1013.

[17] Minotti, G., Menna, P., Salvatorelli, E., Cairo, G. and Gianni, L. (2004) Anthracyclines: Molecular Advances and Pharmacologic Developments in Antitumor Activity and Cardiotoxicity. Pharmacological Reviews, 56, 185-229. http://dx.doi.org/10.1124/pr.56.2.6

[18] Arcamone, F., Cassinelli, G., Fantini, G., Grein, A., Orezzi, P., Pol, C. and Spalla, C. (1969) Adriamycin, 14-Hydroxydaunomycin, a New Antitumor Antibiotic from S. peucetius var. caesius. Biotechnology and Bioengineering, 11, 1101-1110. http://dx.doi.org/10.1002/bit.260110607

[19] Moore, S., Patel, R.P., Atherton, E., Kondo, M., Meienhofer, J. (1976) Synthesis and Some Properties and Antitumor Effects of the Actinomycin Lactam Analog, (Di(1-L-Alpha, Beta-Diaminopropionic))Actinomycin D1. Journal of Medicinal Chemistry, 19, 766-772. http://dx.doi.org/10.1021/jm00228a006

[20] Parker, C., Waters, R., Leighton, C., Hancock, J., Sutton, R., Moorman, A.V., Ancliff, P., Morgan, M., Masurekar, A., Goulden, N., Green, N., Révész, T., Darbyshire, P., Love, S. and Saha, V. (2010) Effect of Mitoxantrone on Outcome of Children with First Relapse of Acute Lymphoblastic Leukaemia (ALL R3): An Open-Label Randomised Trial. Lancet, 376, 2009-2017. http://dx.doi.org/10.1016/S0140-6736(10)62002-8

[21] Madathil, M.M., Bhattacharya, C., Yu, Z., Paul, R., Rishel, M.J. and Hecht, S.M. (2014) Modified Bleomycin Disaccharides Exhibiting Improved Tumor Cell Targeting. Biochemistry, 53, 6800-6810. http://dx.doi.org/10.1021/bi501102z

[22] Galm, U., Hager, M.H., Van Lanen, S.G., Ju, J., Thorson, J.S. and Shen, B. (2005) Antitumor Antibiotics: Bleomycin, Enediynes, and Mitomycin. Chemical Reviews, 105, 739-758. http://dx.doi.org/10.1021/cr030117g

[23] Sparreboom, A., Nooter, K. and Verwej, J. (2002) The Cancer Handbook. John Wiley \& Sons Inc., Hoboken.

[24] Miyagawa, N., Sasaki, D., Matsuoka, M., Imanishi, M., Ando, T. and Sugiura, Y. (2003) DNA Cleavage Characteristics of Non-Protein Enediyne Antibiotic N1999A2. Biochemical and Biophysical Research Communications, 306, 8792. http://dx.doi.org/10.1016/S0006-291X(03)00925-2

[25] Shao, R.G. and Zhen, Y.S. (2008) Enediyne Anticancer Antibiotic Lidamycin: Chemistry, Biology and Pharmacology. Anti-Cancer Agents in Medicinal Chemistry, 8, 123-131. http://dx.doi.org/10.2174/187152008783497055

[26] Bérdy, J. (2012) Thoughts and Facts about Antibiotics: Where We Are Now and Where We Are Heading. The Journal of Antibiotics, 65, 385-395. http://dx.doi.org/10.1038/ja.2012.27

[27] NCI. http://www.cancer.gov/about-cancer/treatment/drugs

[28] Tanaka, N., Okabe, T., Isono, F., Kashiwagi, M., Nomoto, K., Takahashi, M., Shimazu, A. and Nishimura, T. (1985) Lactoquinomycin, a Novel Anticancer Antibiotic. I. Taxonomy, Isolation and Biological Activity. The Journal of Antibiotics, 38, 1327-1332. http://dx.doi.org/10.7164/antibiotics.38.1327

[29] Oh, K.T., Oh, Y.T., Oh, N.M., Kim, K., Lee, D.H. and Lee, E.S. (2009) A Smart Flower-Like Polymeric Micelle for pH-Triggered Anticancer Drug Release. International Journal of Pharmaceutics, 375, 163-169. http://dx.doi.org/10.1016/j.ijpharm.2009.04.005

[30] Xing, T., Mao, C.Q., Lai, B. and Yan, L.F. (2012) Synthesis of Disulfide-Cross-Linked Polypeptide Nanogel Conjugated with a Near-Infrared Fluorescence Probe for Direct Imaging of Reduction-Induced Drug Release. ACS Applied Materials \& Interfaces, 4, 5662-5672. http://dx.doi.org/10.1021/am301600u

[31] Manome, Y., Kobayashi, T., Mori, M., Suzuki, R., Funamizu, N., Akiyama, N., Inoue, S., Tabata, Y. and Watanabe, M. (2006) Local Delivery of Doxorubicin for Malignant Glioma by a Biodegradable PLGA Polymer Sheet. Anticancer Research, 26, 3317-3326.

[32] Acharya, S. and Sahoo, K.S. (2011) PLGA Nanoparticles Containing Various Anticancer Agents and Tumour Delivery by EPR Effect. Advanced Drug Delivery Reviews, 63, 170-183. http://dx.doi.org/10.1016/j.addr.2010.10.008

[33] Loskotová, H. and Brabec, V. (1999) DNA Interactions of Cisplatin Tethered to the DNA Minor Groove Binder Distamycin. European Journal of Biochemistry, 266, 392-402. http://dx.doi.org/10.1046/j.1432-1327.1999.00866.x

[34] Aich, P., Sen, R. and Dasgupta, D. (1992) Role of Magnesium Ion in the Interaction between Chromomycin $A_{3}$ and DNA: Binding of Chromomycin $\mathrm{A}_{3}-\mathrm{Mg}^{2+}$ Complexes with DNA. Biochemistry, 31, 2988-2997. http://dx.doi.org/10.1021/bi00126a021

[35] Aich, P., Sen, R. and Dasgupta, D. (1992) Interaction between Antitumor Antibiotic Chromomycin $\mathrm{A}_{3}$ and $\mathrm{Mg}^{2+}$. I. 
Evidence for the Formation of Two Types of Chromomycin $\mathrm{A}_{3}-\mathrm{Mg}^{2+}$ Complexes. Chemico-Biological Interactions, 83, 23-33. http://dx.doi.org/10.1016/0009-2797(92)90089-4

[36] Mir, M.A. and Dasgupta, D. (2001) Interaction of Antitumor Drug, Mithramycin, with Chromatin. Biochemical and Biophysical Research Communications, 280, 68-74. http://dx.doi.org/10.1006/bbrc.2000.4075

[37] Das, S., Devi, P.G., Pal, S. and Dasgupta, D. (2005) Effect of Complex Formation between $\mathrm{Zn}^{2+}$ Ions and the Anticancer Drug Mithramycin upon Enzymatic Activity of Zinc(II)-Dependent Alcohol Dehydrogenase. Journal of Biological Inorganic Chemistry, 10, 25-32. http://dx.doi.org/10.1007/s00775-004-0607-3

[38] Bassett, S., Urrabaz, R. and Sun, D. (2004) Cellular Response and Molecular Mechanism of Antitumor Activity by Leinamycin in MiaPaCa Human Pancreatic Cancer Cells. Anticancer Drugs, 15, 689-696. http://dx.doi.org/10.1097/01.cad.0000136886.72917.6f

[39] Shirai, R., Shimazawa, R., Shichita, M., Takahashi, M., Hashimoto, Y. and Iwasaki, S. (1995) Cytotoxicity and DNA-Binding Property of Non-Diynene Class of Dynemicins and Aza-Anthraquinones. Nucleic Acids Symposium Series, No. 34, 151-152.

[40] Nasser, M.W., Datta, J., Nuovo, G., Kutay, H., Motiwala, T., Majumder, S., Wang, B., Suster, S., Jacob, S.T. and Ghoshal, K. (2008) Down-Regulation of Micro-RNA-1 (miR-1) in Lung Cancer. Suppression of Tumorigenic Property of Lung Cancer Cells and Their Sensitization to Doxorubicin-Induced Apoptosis by miR-1. Journal of Biological Chemistry, 283, 33394-33405. http://dx.doi.org/10.1074/jbc.M804788200

[41] Kamat, A.M., DeHaven, J.I. and Lamm, D.L. (1999) Quinolone Antibiotics: A Potential Adjunct to Intravesical Chemotherapy for Bladder Cancer. Urology, 54, 56-61. http://dx.doi.org/10.1016/S0090-4295(99)00064-3

[42] Lin, X.P., Wen, Y., Li, M., Chen, Z., Guo, J., Song, Y. and Li, J.L. (2009) A New Strain of Streptomyces avermitilis Produces High Yield of Oligomycin A with Potent Anti-Tumor Activity on Human Cancer Cell Lines in Vitro. Applied Microbiology and Biotechnology, 81, 839-845. http://dx.doi.org/10.1007/s00253-008-1684-y

[43] Langer, S.W., Jensen, P.B. and Sehested, M. (2007) Other Uses of Dexrazoxane: Savene, the First Proven Antidote against Anthracycline Extravasation Injuries. Cardiovascular Toxicology, 7, 151-153. http://dx.doi.org/10.1007/s12012-007-0021-5

[44] Kleinerman, E.S., Zwelling, L.A., Schwartz, R. and Muchmore, A.V. (1982) Effect of L-Phenylalanine Mustard, Adriamycin, Actinomycin D, and 4'-(9-Acridinylamino)Methanesulfon-m-Anisidide on Naturally Occurring Human Spontaneous Monocyte-Mediated Cytotoxicity. Cancer Research, 42, 1692-1695.

[45] Magae, J., Hosokawa, T., Ando, K., Nagai, K. and Tamura, G. (1982) Antitumor Protective Property of an Isoprenoid Antibiotic, Ascofuranone. The Journal of Antibiotics, 35, 1547-1552. http://dx.doi.org/10.7164/antibiotics.35.1547

[46] Magae, J., Nagai, K., Ando, K., Yamasaki, M. and Tamura, G. (1983) Effects of an Antitumor Agent, Ascofuranone, on the Macromolecular Syntheses of Intact Cells. The Journal of Antibiotics, 36, 892-899. http://dx.doi.org/10.7164/antibiotics.36.892

[47] Banerjee, A., Dahiya, M., Anand, M.T. and Kumar, S. (2013) Inhibition of Proliferation of Cervical and Leukemic Cancer Cells by Penicillin G. Asian Pacific Journal of Cancer Prevention, 14, 2127-2130. http://dx.doi.org/10.7314/APJCP.2013.14.3.2127

[48] Bhattacharya, B. and Turos, E. (2012) Synthesis and Biology of N-Thiolated $\beta$-Lactams. Tetrahedron, 68, 1066510685. http://dx.doi.org/10.1016/j.tet.2012.06.012

[49] Huh, A.J. and Kwon, Y.J. (2011) “Nanoantibiotics”: A New Paradigm for Treating Infectious Diseases Using Nanomaterials in the Antibiotics Resistant Era. Journal of Controlled Release, 156, 128-145. http://dx.doi.org/10.1016/j.jconrel.2011.07.002

[50] Lamb, R., Ozsvari, B., Lisanti, C.L., Tanowitz, H.B., Howell, A., Martinez-Outschoorn, U.E., Sotgia, F. and Lisanti, M.P. (2015) Antibiotics That Target Mitochondria Effectively Eradicate Cancer Stem Cells, across Multiple Tumor Types: Treating Cancer Like an Infectious Disease. Oncotarget, 6, 4569-4584. 